\title{
Formation of competence of the future specialist radio engineering profile
}

\section{Lyudmila Martsevo Andreevna}

Design, Manufacture and Maintenance of Radio technical Devices Department, Vinnitsa Technical College, Vinnitsa, Ukraine

\author{
Email address: \\ martseva.1@inbox.ru
}

\section{To cite this article:}

Lyudmila Martsevo Andreevna. Formation of Competence of the Future Specialist Radio Engineering Profile. Science Journal of Education. Vol. 3, No. 1, 2015, pp. 11-15. doi: 10.11648/j.sjedu.20150301.13

\begin{abstract}
Economic conditions in Ukraine led to the need to modernize the system of vocational education. In the light of modern requirements to graduate education, which focuses only on the acquisition of knowledge, is focus on the past. Formation of socially and professionally active person of the future expert calls for new forms, methods and techniques of training students. The article analyzes the main aspects of the formation of competence of the future expert radio engineering profile. Modern manufacturing and service sector require specialists able to be active in rapidly changing conditions. The author discusses the need for complex technical college graduate competencies in accordance with his future professional activity.
\end{abstract}

Keywords: Competence Approach, Training of Students, Competence, Professional Competence, Radio Engineering Profile

\section{Introduction}

Competence approach became the basis for a radical revision of the aims and content of modern education. The essence of the training given to this approach - creating learning situations and diverse activities of students that will generate their desired set of competencies as future professionals.

For the national vocational education transition to competency model (in fact - the optimal connection qualification and competence model) is relevant and important. The objective of the vocational education system has previously been training for mass, relatively stable production with rarely changing technology and constant product range. Now the technology is constantly changing, the production capacity are becoming more flexible, a trend towards further differentiation, specialization and cooperation, decentralization of enterprises, increasing the role of the service sector, etc.

High-tech industries and service sectors require specialists able to exercise over the activity in rapidly changing conditions. One of the clearest examples of these changes is radio companies, as well as research and project-design organizations that work with them. Training (retraining) qualified for these firms and organizations provides new guidance and, above all, the preparation of active, creative personality, capable of long-term development and improvement in the process of formation of professional competence [1].

\section{Main Body}

Competence - a general ability and willingness of the individual to activity based on knowledge and experience that are acquired in the learning process, focused on the independent participation of the individual in the learning process and focus on the successful integration into society.

Competence (as a result of training) - the ability of future specialist to apply the knowledge, skills and personal qualities for a successful career. For the formation of professional competence of future specialists radiotechnical profile should be allocated learning goals (motivational, cognitive, activity, reflexive); motivational support (aimed at the formation of motives and values); information provision (which is used in lectures, practical and laboratory classes, practical training, independent work); tool maintenance (includes a program of action recommendations to teachers); system control and correction, including self-achieve goals.

Formation of professional competence - is, in fact, a complex process of designing the person, its qualities. To determine the skill and form, in our opinion, it is necessary:

- Fully understand the current trends of professional 
activity and the labor market;

- A good understanding of the whole range of functional responsibilities of the relevant specialty (profession) and professional development opportunities;

- Take into account the opinion of employers and other experts;

- To understand the essence of professional activity specific profile;

- Study in detail the qualifications frameworks, state standards and other normative documents;

- Know the potential of the intellectual and creative development of the students who receive certain specialty.

Professional competence is formed throughout a person's life. Initial professional knowledge, skills, values, future specialist laid at school. Enrolling in higher education, students have varying levels of knowledge, experience, values. The task of institution of higher education - to prepare highly qualified specialists in a particular industry professional activity, that is formed on the basis of general education professional knowledge to individuals and society of quality that allow most fully realize themselves in specific types of work [2, p. 8; 7, p. 84-88; 4].

Further development of professional competence - a dynamic process of learning and upgrading of professional experience, which leads to the development of individual competencies, the accumulation of new competences, and this, in turn, provides for the continuous development and self-improvement.

Formation of professional competence of the expert provides professional accounting structure of modern society. It is known that the division of labor as a natural consequence of social development has led to a gradual differentiation of human activities on the profession. The study of the processes of formation and genesis of this phenomenon allows allocating signs of professions and their relationship with the category of "competence":

- Any profession is usually formed by the actions of the objective laws, which implies that the level of professional competence of the expert is determined by objective factors;

- Profession (specialty) always personified, and thus professional competence is personal expression as a product of social need in a particular professional activity and relevant professional and personal qualities;

- Profession (specialty) acquires two ways: by training and / or as a result of long-term practice, that is, the acquisition of professional experience.

The regular evolution of the process of preparing a competent specialist from the natural produce of professional competence in the practical activities to conscious of its formation in the framework of the educational process indicates that the path of vocational training is more productive.

Formation of competence linked with the mastery of the future expert modes of activity in the process of mastering a variety of practical experience. Do this only with the help of inheritance, effective in the early stages of learning, it is impossible. Future specialist begins to conduct its training and production activities, integrating learning outcomes and creating their own "resource pack" - professional (educational and professional) experience.

Graduates seek to ensure that the maximum acquire the necessary skills to perform standard professional features, as it is a set of reclaimed ways of life is of interest, in demand by employers. However, these functions, as well as the acquired competence of the future expert, are relevant only within a certain period of time (for radio technicians quite small - 2-3 years, with a tendency to decrease), and then to be adjusted in relation to scientific, technical and socio-economical changes . During the training students need to develop and install a conscious need to continuously enhance their skills, improving the already acquired competencies throughout the period of active life.

Modern requirements for training of future professionals of radio engineering profile involve achieving an integrated outcome of vocational education - to form a set of key, of general and professional competencies.

Key competences cause unity of knowledge and skills, universal ability and willingness to perform a wide range of applications - from personal to social and general professional competence and professional readiness of experts to characterize his career.

The problem of formation of competence to deal with virtually all researchers in the field of theory and methodology of professional education. It should be noted that in the models of the future specialist, classifications professional activities, training programs radiotechnical profile does not fully take into account the specifics of the industry and the impact of industrial relations in the process of becoming a specialist. More precisely, only the obvious features of these processes, but modern radio engineering profile specialists work not only in the "man - a technical device" or "man - machine", and in more complex systems such as "subject - object - subject". In addition, each component of the system in a certain way, directly or indirectly affects the personality specialist radio technology.

In the last 15-20 years, scientists have developed and offered various options for a range of professional competence of specialists, particularly engineers and technicians, in order to build specialists based models and models of professional education.

According to V.I. Baydenko [3], make a list of competencies for any specialty (including technical profile) is not difficult, but it is much more difficult to justify methodologically correct.

In Ukraine, as well as in foreign countries, educational systems provide for the existence of different classifications of competences necessary technical specialists.

According to the "Glossary of terms of the labor market, the development of standards of educational programs and curricula" there are four models of determining the necessary competencies, based on:

- parameters of the individual; 
- performing tasks and activities;

- production functions;

- management of the results [4].

Competency model based on the qualities of the individual professional development is built on moral, spiritual and personal qualities of the person. Educational programs, curriculum and assessment system of educational achievements with the focus on the selection and improvement of academic abilities of students.

Competency model that focuses on the performance of tasks aimed at the development of the standard (algorithmic) procedures and operations (the study of the process of work, working methods, etc.). The curriculum and assessment methods allow a person to develop a specific set of skills to practice in their use in professional work based on them, as well as addressing specific tasks and achieve goals.

Competency model of the future expert in accordance with its production functions aimed at achieving concrete results. This model is common in the preparation of students of those professions where the effectiveness of professional activity is determined by the final results. In this case, the formation of the assessment of competence is based on the fact that the expert is able to do, rather than what he knows.

Model performance management characterizes professional activity as a function of the future expert human social context in which it is recognized list of professional responsibilities, and training programs of professional training aimed at creating a set of competencies required for graduates in employment.

Many scientists believe that the combination of the first and second models - fundamental to the training of future technical specialists $[4$, p. 69; 9].

The analysis of 85 competent specialists defined by European explorers in the Tuning project, which aims at harmonizing educational structures [5], suggests that many of them cannot be achieved in the process of learning, even by the Master's program. Therefore, the formations of some competencies possible within postgraduate education and professional work in the workplace. This necessitates the selection of competencies (and their descript) for each educational qualification level of training. [6, p.233]. Without a solution to this issue is not clearly identifiable results of training students, regardless of where, when and how they are received education subsystem (eg qualification of junior specialist radio engineering profile - in the higher vocational school, technical college or a structural unit of the Technical University). It is also important to agree on the framework for qualifications of each level of vocational education with the gradual training.

Let us consider a brief characterization of the backbone of professional competence of the future expert radio engineering profile, highlighting that it is necessary to form students during their studies. [7, p. 570-576; 8, p. 156-158].

\subsection{Instrumental Competence}

Professionally-subject competence the main competence of the expert. It characterizes the overall level of preparedness of radio technology - the integration unity of the natural sciences, social and human, organizational, economic, general technical and vocational-oriented knowledge and skills that allow him to analyze the professional information, production situation, choose the appropriate ways of activities, forms and methods of professional solutions assignments.

Informative competence of the future expert-radio technology as a component of professional competence includes the ability to receive, process and adequate use of the information in the course of professional activities with the help of specialized software. Occupies a special place ready to use techniques and methods of activity aimed at computerization of production processes through the use of complex functional diverse information tools and technologies related to market research, design of industrial products, working with design documentation, engineering calculations.

Creative competence - ability and focus on optimal improvement of the technical system, the allocation of the laws of its development, the use of forms and methods of creative activity in various fields, as well as readiness for creative growth. This competence is manifested in a creative initiative, flexibility, ownership methods of technical creativity.

Innovative competence reflects the orientation, ability and willingness to radio technology for strategic foresight innovative development company, organization, change the objects of professional activity in accordance with the goals and objectives.

Competence self determines readiness specialist to continuous learning and self-development based on the desire to improve their professional, intellectual and creative potential.

\subsection{Professional and Personal Competencies}

Social and motivational competence is an indication of awareness of the social value of the profession radio technology, the ability to take responsibility for the proposed new production and organizational and technical approaches and their implementation. This competence describes the professional and ethical culture, ideals of life and values.

Communication competence describes features communication activities and radios, the specifics of its communication with the administration, colleagues, subordinates, employees and customers, representatives of partner organizations. This expertise is reflected in the willingness and ability to productive adverse communication in the socio-professional environment (establishment and expansion of business contacts).

Leadership competencies characterizes the direction of a specialist in the field of engineering and technology to achieve high results, reflects his desire for success. In junior specialist - middle managers important features is the ability to clear and understandable way to express their thoughts, reliability and consistency in business dealings.

Emotional competence desire and ability to control their specialist emotional state in the communication process. 
Specialist radio technician must be skilled in control of his emotional state, maintaining interpersonal relationships among their subordinates, colleagues and customers.

Role competence characterizes professional role versatility junior specialist radio technology, which integrates functional and social contexts of its activities. Competence includes effective performance of their professional duties, understanding the specifics of job duties middle managers (designer, expert consultant, team leader).

Corporate competence reflects a system of value orientations and manifested in the corporate culture of the professional community. This competence involves motivational readiness for socially responsible behavior and professional interaction, responsibility for decisions, quality and safety designed electronic devices and systems.

\subsection{Organizational and Managerial Competence}

Target competence specialist radio technology provides the ability to formulate professional goals of different levels and areas: individual and group; current and future; the real and the ideal; global and partial. Sense of purpose - driving conditions, the implementation of professional tasks.

Project competence includes the ability to specialist radio engineering profile foresee the results of its operations, to determine the sequence of their actions to achieve a specific professional goals combine strategic and immediate goals.

Monitoring of radio engineering specialist competence profile describes the ability to monitor production processes, repair or maintenance of radio systems, a comparison of the predicted and actual results, diagnosis, evaluation, identification of the dynamics and forecasting results.

Career competence is presented as a focus on career development, the ability to build a personal career strategy. Junior specialist should be responsible for their career path, be skilled in self-efficacy, be confident, their readiness, professional opportunities [7, p. 570-576].

Reflexive competence related to the ability of junior specialist to evaluate their own and collective professional activities. Experience professional-radio technology is the source of his career, when he becomes the object of a structured analysis; while non-reflexive practice is not the impetus for the development, and later leads to professional degradation [8, p. 153-161].

\subsection{For Professional Qualifications Competence of Junior Specialists in Radio Engineering Profile Meet the Qualifications Include}

1) domain knowledge:

- Modern element base, which is used in the development of radio, telecommunication and computing means;

- Software for the design of radio-electronic devices and systems, computer-aided design of electronic equipment;

- Schematic design components and devices intended for the generation, formation, reception and amplification of radio signals;

- Current knowledge in the field of digital signal processing techniques in digital implementation of radio systems;

- Methods and tools for professionally-oriented engineering and computer graphics;

- Methods and tools for professionally-oriented engineering and computer graphics;

- Modern production technology of electronic equipment and instruments;

2) Cognitive skills in the professional field:

- Ability to use professional and specialized knowledge and practical skills in fundamental disciplines in the development and manufacture of radio-electronic devices;

- Ability to apply knowledge and skills to solve qualitative and quantitative objectives;

- Systems engineering design skills;

- ability to enter and process text, graphic and multimedia information;

- Possession of specialized information communication technology and software, in particular, computer-aided design, the use of modern computer technology in the radio activity;

- The ability to create, evaluation, synthesis and interpretation of data;

- Skills both written and oral presentation of professional information.

3) Practical skills in the subject area:

- Designing, researching, repairing electronic equipment broad functionality;

- Apply the skills of organizing the production and operation of radio-electronic devices and systems;

- Use specialized software;

- Be able to work with specialized instrumentation;

- To carry out maintenance and repair of appliances and equipment;

- Have the skills of innovation and invention.

\section{Conclusions}

Professional competence of junior specialist's radiotechnical profile determined a wide spectrum generated in the process of learning competencies reflects the specific subject-object and subject-subject relations specialist types in a professional environment. Subject-object relationship is mainly determined by the subject-specialist instrumental readiness to professional activity; subject-subject - characterize the psychological readiness, personal professional qualities, the ability to form social relationships in a professional environment.

Formation of competence of junior specialist - is the process of formation and development of the population (group) professionally important qualities of the person, which express the whole structure and characteristics of their professional activities on the basis of individual psychological characteristics of the particular subject of this activity. This process is done by the formation of refraction influence the educational and social environment through the development of the personality factors specialist [9-12]. 


\section{References}

[1] Piralova O. F. Diagnosis competent engineer. Specialty 190301.65 - "locomotive": monograph [Electron resource] / Moscow: Academy of Natural Sciences, 2010. - 88 p. - mode of access: http://www.rae.ru/monographs/92

[2] Bila O.O. Competence professional self: pedagogical principles of formation in high school: monograph / O.O. Bila, T.R. Humennykova, Y. Kinchuk. - Ismail, Ismail State Humanitarian University. 2007. - 236 p. (in Ukraine)

[3] Baydenko V.I. Competence: competence-based approach to development: lecture slides (Author's version) / V.I. Baydenko - M. Research Center challenges the quality of training, 2004. p. 25-30. (in Russian)

[4] Boychuk Y.D. Research and development technical college students as pedagogical conditions of professional competence / Y.D. Boychuk // Vestnik HNADU. - 2013. - vol. 60. - p. 7-11. (in Ukraine)

[5] Piralova O. Modern training engineers professional disciplines in a multi-level training. Monograph /M.: Publisher "Academy of Natural History", 2009.

[6] Paper of National Education of Ukraine / T.F. Alekseyenko, V.M. Anischenko, G.O. Ball [et al.]; NAPS Ukraine. - K: Inform. System, 2010. - 342 p. (in Ukraine)

[7] Avdeeva A.P. Competence model of professional elite in the field of engineering and technology // Education \& Science: Scientific and technical electronic edition http://technomag.bmstu.ru/doc/589246.html., p. 570-576. (in Russian)

[8] Glossary of terms of the labor market, the development of standards of educational programs and curricula. European Training Foundation. - Turin: European Training Foundation, 1997. - $160 \mathrm{p}$.

[9] Kovalchuk V.V. The essential characteristics of meaningful category of "professional competence" as an indicator of the level of professional training of students // Problems of Engineering and Pedagogical sciences. 2007. - № 18. - p. 84-88.

[10] Kutsak L.V. Features of formation of professional competence of future teachers of labor studies in terms of training // Problems and prospects of forming national humanitarian and technical elite. - vol. 26. - Kharkov: NTU, 2010. - p. 153-161.

[11] Petruneva R.M. Model professional engineer from the activities of competence: monograph /- Volgograd: Polytechnic, $2007-145 \mathrm{p}$.

[12] TUNING Educational Structuresin Europe. [Electron resource] - Mode of access: $\mathrm{http}: / /$ www.tuning.unideusto.org/tuningeu/index.php?option= content $\&$ task $=$ view\&id=210\&Itemid= 236 . 